\title{
Thirty-day outcomes after postnatal myelomeningocele repair: a National Surgical Quality Improvement Program Pediatric database analysis
}

\author{
Jacob Cherian, MD, ${ }^{1,2}$ Kristen A. Staggers, MS, 1,2 I-Wen Pan, PhD, ${ }^{1,2}$ Melissa Lopresti, MD, ${ }^{1,2}$ \\ Andrew Jea, MD, ${ }^{1,2}$ and Sandi Lam, MD, MBA ${ }^{1,2}$ \\ 'Division of Pediatric Neurosurgery, Texas Children's Hospital, and 'Department of Neurosurgery, Baylor College of Medicine, \\ Houston, Texas
}

\begin{abstract}
OBJECTIVE Due to improved nutrition and early detection, myelomeningocele repair is a relatively uncommon procedure. Although previous studies have reviewed surgical trends and predictors of outcomes, they have relied largely on single-hospital experiences or on databases centered on hospital admission data. Here, the authors report 30-day outcomes of pediatric patients undergoing postnatal myelomeningocele repair from a national prospective surgical outcomes database. They sought to investigate the association between preoperative and intraoperative factors on the occurrence of 30-day complications, readmissions, and unplanned return to operating room events.
\end{abstract}

METHODS The 2013 American College of Surgeons National Surgical Quality Improvement Program Pediatric database (NSQIP-P) was queried for all patients undergoing postnatal myelomeningocele repair. Patients were subdivided on the basis of the size of the repair $(<5 \mathrm{~cm}$ vs $>5 \mathrm{~cm})$. Preoperative variables, intraoperative characteristics, and postoperative 30-day events were tabulated from prospectively collected data. Three separate outcomes for complication, unplanned readmission, and return to the operating room were analyzed using univariate and multivariate logistic regression. Rates of associated CSF diversion operations and their timing were also analyzed.

RESULTS A total of 114 patients were included; 54 had myelomeningocele repair for a defect size smaller than $5 \mathrm{~cm}$, and 60 had repair for a defect size larger than $5 \mathrm{~cm}$. CSF shunts were placed concurrently in $8 \%$ of the cases. There were 42 NSQIP-defined complications in 31 patients (27\%); these included wound complications and infections, in addition to others. Postoperative wound complications were the most common and occurred in 27 patients (24\%). Forty patients (35\%) had at least one subsequent surgery within 30 days. Twenty-four patients $(21 \%)$ returned to the operating room for initial shunt placement. Unplanned readmission occurred in $11 \%$ of cases. Both complication and return to operating room outcomes were statistically associated with age at repair.

CONCLUSIONS The NSQIP-P allows examination of 30-day perioperative outcomes from a national prospectively collected database. In this cohort, over one-quarter of patients undergoing postnatal myelomeningocele repair experienced a complication within 30 days. The complication rate was significantly higher in patients who had surgical repair within the first 24 hours of birth than in patients who had surgery after the 1st day of life. The authors also highlight limitations of investigating myelomeningocele repair using NSQIP-P and advocate the importance of disease-specific data collection. http://thejns.org/doi/abs/10.3171/2016.1.PEDS15674

KEY WORDS myelomeningocele; National Surgical Quality Improvement Program; NSQIP; pediatric; spina bifida; readmission; outcomes; congenital

$\mathrm{M}$ YELOMENINGOCELE repair is a relatively uncommon procedure. ${ }^{7}$ Much of this has been attributed to improved nutrition and early detection. Prior studies have examined surgical trends and predictors of outcomes, mostly relying on single-hospital experiences or on hospital administrative discharge data. ${ }^{6,7}$
The American College of Surgeons National Surgical Quality Improvement Program Pediatric (NSQIP-P) database (https://www.facs.org/quality-programs/pediatric), developed in collaboration with the American Pediatric Surgical Association, is the first national, prospectively assembled, surgical outcomes database for the pediatric

ABBREVIATIONS ASA = American Society of Anesthesiologists; CPT = Current Procedural Terminology; NSQIP-P = National Surgical Quality Improvement Program Pediatric.

ACCOMPANYING EDITORIAL See pp 413-415. DOI: 10.3171/2016.2.PEDS1639.

SUBMITTED November 16, 2015. ACCEPTED January 20, 2016.

INCLUDE WHEN CITING Published online June 3, 2016; DOI: 10.3171/2016.1.PEDS15674. 
population. ${ }^{4,11}$ In this study, we used the NSQIP-P database to investigate the association between preoperative and intraoperative factors on the occurrence of 30-day complication, unplanned readmission, and return to operating room in pediatric patients undergoing postnatal myelomeningocele repair.

\section{Methods}

The NSQIP-P database is composed of a national sample of cases in patients younger than 18 years old. The 2013 NSQIP-P public use file includes more than 60,000 de-identified cases from more than 50 centers. A listing of participating NSQIP-P children's hospitals is provided by the American College of Surgeons (https://www.facs. org/search/nsqip-participants). Nearly 150 variables are prospectively collected, encompassing preoperative risk factors, intraoperative variables, and 30-day postoperative morbidity and mortality outcomes. At each participating center, trained surgical clinical reviewers identify cases, collect data by review of medical records, and track 30day outcomes for each patient. This process involves contacting families for 30-day outcomes if no medical record events are noted in that time frame.

Using NSQIP-P data from the year 2013, we queried all cases with a Current Procedural Terminology (CPT) code and description for repair of myelomeningocele: repair of myelomeningocele larger than $5 \mathrm{~cm}$ in diameter (CPT 63706) and repair of myelomeningocele smaller than $5 \mathrm{~cm}$ in diameter (CPT 63704). To better target the appropriate population of interest, cases were excluded if the surgery was performed 30 days after birth. Patient variables included age at repair, gestational age, sex, race and ethnicity, weight, and American Society of Anesthesiologists (ASA) class. Intraoperative factors included operative time in minutes, use of a second subspecialty surgery team for closure, and simultaneous shunt placement. Thirty-day outcome measures included NSQIP-P-defined postsurgical complications, return to operating room, and unplanned readmissions. When available, reasons for readmission were noted and analyzed in those patients for whom International Classification of Diseases, Ninth Revision diagnosis codes were provided. Return to operating room events were categorized by CPT codes.

Stata software (version 14, StataCorp) was used for statistical analysis. Two-sided Fisher's exact test $p$ values were calculated to analyze contingency tables of comparison groups. For analysis of statistical significance, a $\mathrm{p}$ value threshold $<0.05$ and $95 \%$ confidence intervals were used. Three primary outcome measures were used for univariate logistic regression analysis: 30-day complications, return to operating room events, and unplanned readmissions. Several patients had multiple complications and return to operating room events. Death within 30 days was not used in this analysis due to only 2 events, resulting in the inability to calculate odds ratios with this variable. For logistic regression analysis, confidence intervals were calculated and $p$ values were estimated by Wald approximation. Factors with $\mathrm{p}<0.25$ in the univariate analysis were used in multivariate logistic regression to attempt to adjust for confounders. Akaike's information criterion and Bayesian information criterion were calculated to compare model fit. The NSQIP-P database is de-identified and constitutes nonhuman subjects research with exempt status from the Baylor College of Medicine Institutional Review Board.

\section{Results}

One hundred twenty-five patients were identified with the defined CPT codes. Eleven patients were excluded because the surgery was performed more than 30 days after birth. The remaining 114 patients were included in the analysis. The median age at time of surgery was 1 day (SD 1.58 days, range $0-14$ days). Fifty-four patients had myelomeningocele repair for a defect smaller than $5 \mathrm{~cm}$, and 60 had repair for a defect larger than $5 \mathrm{~cm}$. About half of the patients were male (52\%); most were white (74\%) and nonHispanic (79\%). The majority of patients had a gestational age of at least 37 weeks (80\%) and weighed at least 2500 $\mathrm{g}(87 \%)$. At least $41 \%$ of procedures were performed at the same center at which the patients were born.

Shunts were recorded as being placed concurrently in $8 \%$ of cases and on a delayed basis within 30 days in $21 \%$ of patients at a median of 7 days after the initial operation. A second service was used for closure in $12 \%$ of cases; this practice was slightly more common in defects larger than $5 \mathrm{~cm}$ (15\% vs 9\%). The median operative time was about 93 minutes and did not differ significantly based on defect size. Table 1 contains a full list of patient and operative factors.

There were a total of 42 NSQIP-defined complications in 31 patients (27\%). Wound complications were the most common and were identified in $24 \%$ of cases. The majority of returns to the operating room within 30 days of myelomeningocele repair were for initial hydrocephalus treatment (shunt placement or ventriculocisternostomy). Figure 1 illustrates the indications for return to operating room events.

Unplanned readmission within 30 days occurred in 12 cases (11\%) at a median of 20 days after the initial operation. In 7 of these cases, hydrocephalus or wound disruption was given as the reason for readmission. No reason was recorded in 5 cases of readmission. There were no statistically significant differences in the occurrence of 30day events based on defect size. Table 2 details postoperative events occurring within 30 days of the initial surgery.

Age at repair was significantly associated with both postoperative complications and return to operating room events. For patients who had myelomeningocele repair within the first 24 hours of birth, the odds of having a complication within 30 days were 3.74 times larger than the odds for a patient having repair at $\geq 1$ day of age (OR $3.74,95 \%$ CI $1.45-9.63 ; p=0.01$ ). Rates of return to operating room were higher in patients who had myelomeningocele repair within 24 hours of birth compared with $\geq 1$ day of age (OR 3.09, 95\% CI 1.22-7.86; $\mathrm{p}=0.02$ ). Figure 2 displays each 30 -day NSQIP-P outcome rate by age at repair. Detailed statistics for the univariate logistic regression analysis can be found in Table 3 .

Factors with a $\mathrm{p}$ value $<0.25$ were selected for possible inclusion in multivariate logistic regression analy- 
TABLE 1. Patient characteristics and perioperative factors

\begin{tabular}{|c|c|c|c|}
\hline \multirow[b]{2}{*}{ Variable } & \multicolumn{3}{|c|}{ Myelomeningocele Repair Size } \\
\hline & $<5 \mathrm{~cm}$ & $>5 \mathrm{~cm}$ & Total \\
\hline No. of patients & 54 & 60 & 114 \\
\hline No. of males & $29(54)$ & $30(50)$ & $59(52)$ \\
\hline \multicolumn{4}{|l|}{ Race } \\
\hline Other/unknown & $10(19)$ & $3(5)$ & $13(11)$ \\
\hline Black/African American & $8(15)$ & $9(15)$ & $17(15)$ \\
\hline White & $36(67)$ & $48(80)$ & $84(74)$ \\
\hline \multicolumn{4}{|l|}{ Ethnicity } \\
\hline Non-Hispanic & $42(78)$ & $48(80)$ & $90(79)$ \\
\hline Hispanic & $9(17)$ & $11(18)$ & $20(18)$ \\
\hline Missing & $3(6)$ & $1(2)$ & $4(4)$ \\
\hline \multicolumn{4}{|l|}{ Age at repair in days } \\
\hline 0 & $8(15)$ & $16(27)$ & $24(21)$ \\
\hline$\geq 1$ & $46(85)$ & $44(73)$ & $90(79)$ \\
\hline \multicolumn{4}{|l|}{ Gestational age in wks } \\
\hline$<37$ & $14(26)$ & $9(15)$ & $23(20)$ \\
\hline$\geq 37$ & $40(74)$ & $51(85)$ & $91(80)$ \\
\hline \multicolumn{4}{|l|}{ Weight category in $\mathrm{g}$} \\
\hline$<2500 \mathrm{~g}$ & $10(19)$ & $5(8)$ & $15(13)$ \\
\hline$\geq 2500 \mathrm{~g}$ & $44(81)$ & $55(92)$ & $99(87)$ \\
\hline \multicolumn{4}{|l|}{ ASA class } \\
\hline$\leq \|$ & $22(41)$ & $20(33)$ & $42(37)$ \\
\hline$\geq|I|$ & $32(59)$ & $39(65)$ & $71(62)$ \\
\hline Missing & $0(0)$ & $1(2)$ & $1(1)$ \\
\hline \multicolumn{4}{|l|}{ Op time, in mins } \\
\hline Median & 96.5 & 93 & 93 \\
\hline IQR & $60-132$ & $56-159$ & $58-143$ \\
\hline Simultaneous shunt placement & $3(6)$ & $6(10)$ & $9(8)$ \\
\hline Second-team wound closure & $5(9)$ & $9(15)$ & $14(12)$ \\
\hline
\end{tabular}

sis. However, the addition of potential effect modifiers did not improve the fit of the models for all three 30-day outcomes. The best fitting models, according to Akaike's information criterion and Bayesian information criterion, contained only one predictor variable for each outcome. Age at repair was the single strongest predictor for both postoperative complications and return to operating room events. Weight less than $2500 \mathrm{~g}$ was a predictor for unplanned readmissions within 30 days. The final logistic regression models are listed in Table 4.

\section{Discussion}

This study used data from the NSQIP-P to examine perioperative outcomes from postnatal myelomeningocele repair. Recent studies involving myelomeningocele repair have relied on single-center experiences and national databases based on nonlongitudinal hospital discharge data. $2,6,7,20$ As myelomeningocele repair has become less common, ${ }^{9}$ most individual centers have limited exposure to interpret perioperative outcomes. The NSQIP-P database allows for examination of 30-day surgical outcomes
TABLE 2. Thirty-day postoperative complications and events

\begin{tabular}{|c|c|c|c|}
\hline \multirow[b]{2}{*}{ Variable } & \multicolumn{3}{|c|}{ Myelomeningocele Repair Size } \\
\hline & $<5 \mathrm{~cm}$ & $>5 \mathrm{~cm}$ & Total \\
\hline No. of patients & 54 & 60 & 114 \\
\hline Any NSQIP complication & $13(24)$ & $18(30)$ & $31(27)$ \\
\hline $\begin{array}{l}\text { Infection (superficial, deep, organ } \\
\text { space) }\end{array}$ & $4(7)$ & $3(5)$ & $7(6)$ \\
\hline Superficial dehiscence & $5(9)$ & $8(13)$ & $13(11)$ \\
\hline Wound disruption & $3(6)$ & $4(7)$ & $7(6)$ \\
\hline Unplanned intubation & $2(4)$ & $2(3)$ & $4(4)$ \\
\hline Urinary tract infection & $2(4)$ & $1(2)$ & $3(3)$ \\
\hline Seizure & $1(2)$ & $1(2)$ & $2(2)$ \\
\hline Intraventricular hemorrhage & $0(0)$ & $1(2)$ & $1(1)$ \\
\hline Bleeding/transfusion & $1(2)$ & $3(5)$ & $4(4)$ \\
\hline Systemic sepsis & $0(0)$ & $1(2)$ & $1(1)$ \\
\hline \multicolumn{4}{|l|}{ Unplanned readmission } \\
\hline Hydrocephalus & $1(2)$ & $3(5)$ & $4(4)$ \\
\hline Wound disruption & $2(4)$ & $1(2)$ & $3(3)$ \\
\hline Other & $3(6)$ & $2(3)$ & $5(4)$ \\
\hline \multicolumn{4}{|l|}{ Return to op room w/in 30 days } \\
\hline Initial shunt placement & $15(28)$ & $9(15)$ & $24(21)$ \\
\hline Ventriculocisternostomy & $2(4)$ & $0(0)$ & $2(2)$ \\
\hline Shunt revision or removal & $2(4)$ & $3(5)$ & $5(4)$ \\
\hline Repair of CSF leak & $1(2)$ & $3(5)$ & $4(4)$ \\
\hline Wound repair & $2(4)$ & $2(3)$ & $4(4)$ \\
\hline Missing & $1(2)$ & $0(0)$ & $1(1)$ \\
\hline Death & $1(2)$ & $1(2)$ & $2(2)$ \\
\hline
\end{tabular}

collected prospectively and on a larger scale from multiple centers. ${ }^{11,21}$

In this study, wound complications, including both dehiscence and infection, were the most common complications reported in the 30-day postoperative period. These results echo other published experiences. ${ }^{8}$ Roughly half of these wound problems were superficial dehiscence. Seven percent of all cases had return to operating room events within 30 days for revision of disrupted wounds with or without accompanying CSF leak. Use of a second surgical team to assist with closure was seen in $12 \%$ of cases and was more common in cases with larger defects $(15 \%$ vs $9 \%$ ). This percentage is less than the $25 \%$ of defects reported in published series that could not be closed primarily with skin undermining, requiring plastic surgery involvement for coverage. ${ }^{15}$ Neither second-team wound closure nor size of myelomeningocele defect had any significant impact on perioperative complications or events.

Unplanned readmission within 30 days occurred in 12 cases (11\%) at a median of 20 days after the initial surgery. In 7 of the 12 cases, hydrocephalus or wound disruption was recorded as the reason for readmission. No reason was recorded in 5 of 12 cases of readmission, which is a shortcoming in the NSQIP-P database that represents an opportunity for enhancement in the future. The program would have higher completion of data fields if there were "hard stops" with required entry. There were no documented complications or readmissions for symptomatic Chiari II 


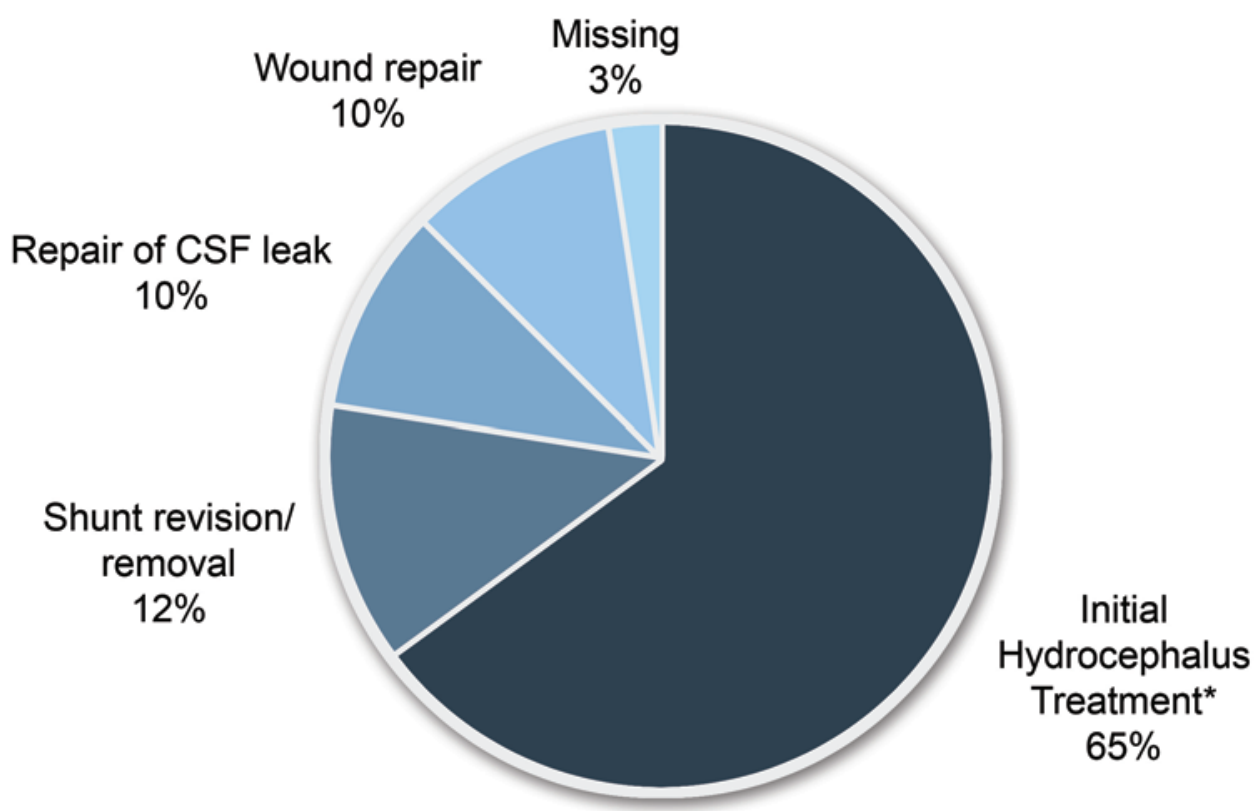

FIG. 1. Reason for return to the operating room within 30 days. *Shunt or ventriculocisternostomy. Figure is available in color online only.

malformation in this cohort; it is not known if this was not observed in this patient cohort, not documented in medical records, or not recognized by clinical reviewers. There were no surgeries for decompression of Chiari II malformation within 30 days of myelomeningocele repair in this cohort. This finding fits with published literature, which suggests that Chiari II decompression surgery is rare, especially in neonates within the first 1-2 months of life. While Chiari II decompression surgeries in infants to relieve mechanical compression have been reported, patient collection for relatively small series spanned multiple years at high-volume pediatric institutions. The absence of an observed event (surgery on Chiari II) in this 1-year NSQIP-P cohort may not be unexpected. . $^{13,14,19}$

Weight was a significant predictor for unplanned readmissions within 30 days. Infants weighing less than 2500 $\mathrm{g}$ were at increased risk for readmission (OR 4.14, 95\% CI $1.07-16.01 ; p=0.04)$. Prematurity and ASA class were not significantly associated with perioperative events in this study cohort, although the sample size of 114 patients may be underpowered to detect specific influences of prematurity and low birth weight given the possible spectrum of presentation. Multidisciplinary involvement, care coordination, and discharge planning for this at-risk neonatal population warrant careful attention.

Most myelomeningocele closure surgeries in this cohort were performed within the first few days of life, consistent with the recommended practice that timing of surgery take place within 72 hours of life. ${ }^{10}$ Myelomeningocele repairs performed in infants within 24 hours of birth compared with those performed more than 24 hours after birth were associated with significantly increased odds for postoperative complications in this study (OR 3.74, 95\% CI 1.459.63; $\mathrm{p}=0.01$ ). In a study using the 2000 to $2010 \mathrm{Kids}$ Inpatient Database and Nationwide Inpatient Sample, Attenello et al. concluded that timing of myelomeningocele repair done at 2 or more days after birth was associated with increased infection rates. ${ }^{2}$ Taken together with the lit-

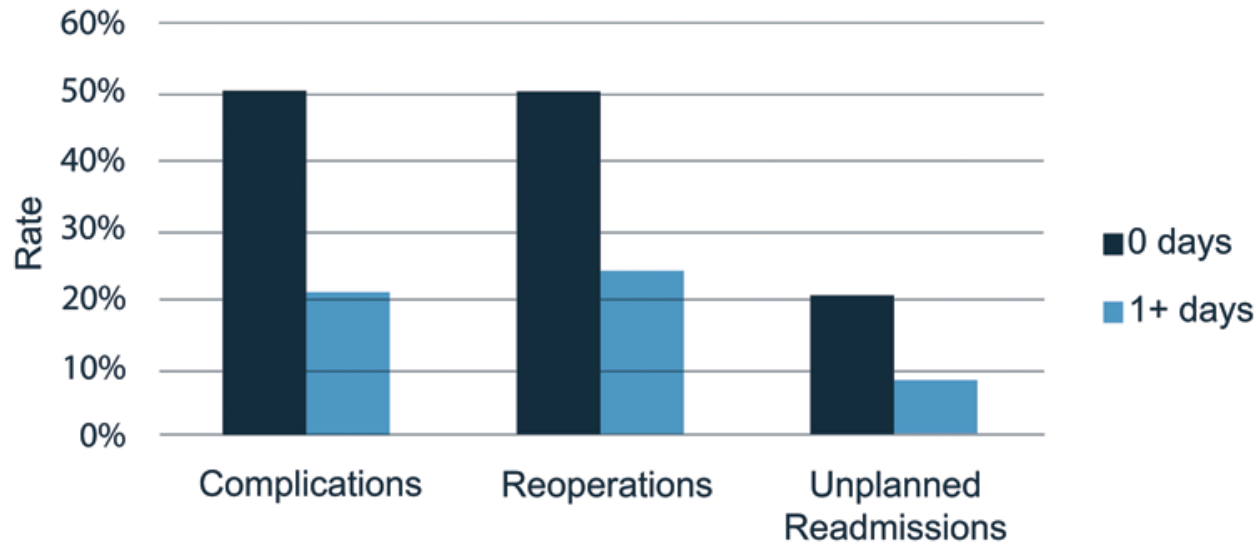

FIG. 2. Thirty-day outcomes by age at repair. Figure is available in color online only. 
TABLE 3. Univariate logistic regression for association of patient and procedure characteristics with 30-day outcomes*

\begin{tabular}{|c|c|c|c|c|c|c|}
\hline \multirow[b]{2}{*}{ Variable } & \multicolumn{2}{|c|}{ Complication w/in 30 Days } & \multicolumn{2}{|c|}{ Return to OR w/in 30 Days } & \multicolumn{2}{|c|}{ Unplanned Readmission w/in 30 Days } \\
\hline & OR $(95 \% \mathrm{Cl})$ & p Value & OR $(95 \% \mathrm{Cl})$ & p Value & OR $(95 \% \mathrm{Cl})$ & $p$ Value \\
\hline \multicolumn{7}{|l|}{ Age at repair } \\
\hline 0 days & $3.74(1.45-9.63) \dagger$ & $0.01 \dagger$ & $3.09(1.22-7.86) \dagger$ & $0.02 \dagger$ & $3.12(0.89-10.90)$ & 0.08 \\
\hline$\geq 1$ day & Reference & & Reference & & Reference & \\
\hline \multicolumn{7}{|l|}{ Gender } \\
\hline Male & $2.05(0.87-4.81)$ & 0.10 & $1.79(0.78-4.05)$ & 0.17 & $2(0.57-7.06)$ & 0.28 \\
\hline Female & Reference & & Reference & & Reference & \\
\hline \multicolumn{7}{|l|}{ Race } \\
\hline White & Reference & & Reference & & Reference & \\
\hline Black/African American & $0.77(0.23-2.60)$ & 0.67 & $0.54(0.14-2.03)$ & 0.36 & $2.04(0.48-8.63)$ & 0.34 \\
\hline Other/unknown & $0.75(0.19-2.96)$ & 0.68 & $2.92(0.89-9.58)$ & 0.08 & $0.79(0.09-6.91)$ & 0.83 \\
\hline \multicolumn{7}{|l|}{ Ethnicity } \\
\hline Hispanic & $1.57(0.56-4.41)$ & 0.39 & $1.11(0.39-3.22)$ & 0.84 & $2.96(0.78-11.32)$ & 0.11 \\
\hline Non-Hispanic & Reference & & Reference & & Reference & \\
\hline \multicolumn{7}{|l|}{ Gestational age } \\
\hline$<37$ wks & Reference & & Reference & & Reference & \\
\hline$\geq 37$ wks & $1.07(0.38-3.03)$ & 0.89 & $1.68(0.57-4.98)$ & 0.35 & $3.03(0.37-24.72)$ & 0.30 \\
\hline \multicolumn{7}{|l|}{ Weight category } \\
\hline$<2500 \mathrm{~g}$ & $1.97(0.64-6.10)$ & 0.24 & $0.84(0.25-2.84)$ & 0.77 & $4.14(1.07-16.01) \dagger$ & $0.04 \dagger$ \\
\hline$\geq 2500 \mathrm{~g}$ & Reference & & Reference & & Reference & \\
\hline \multicolumn{7}{|l|}{ ASA class } \\
\hline$\leq 11$ & Reference & & Reference & & Reference & \\
\hline$\geq 111$ & $1.03(0.43-2.45)$ & 0.95 & $0.66(0.29-1.50)$ & 0.32 & $0.81(0.24-2.73)$ & 0.73 \\
\hline \multicolumn{7}{|l|}{ Myelomeningocele defect size } \\
\hline$<5 \mathrm{~cm}$ & Reference & & Reference & & Reference & \\
\hline$>5 \mathrm{~cm}$ & $1.35(0.59-3.11)$ & 0.48 & $0.61(0.27-1.38)$ & 0.24 & $0.89(0.27-2.94)$ & 0.85 \\
\hline Op time, mins & $1.00(0.99-1.01)$ & 0.43 & $1.00(0.99-1.01)$ & 0.96 & $0.99(0.98-1.01)$ & 0.33 \\
\hline \multicolumn{7}{|c|}{ Simultaneous shunt placement } \\
\hline No & Reference & & Reference & & Reference & \\
\hline Yes & $0.31(0.04-2.61)$ & 0.28 & NA $\ddagger$ & NA $\ddagger$ & $1.07(0.12-9.36)$ & 0.95 \\
\hline \multicolumn{7}{|l|}{ Second-team wound closure } \\
\hline No & Reference & & Reference & & Reference & \\
\hline Yes & $1.08(0.31-3.74)$ & 0.90 & $0.35(0.07-1.68)$ & 0.19 & $0.62(0.07-5.23)$ & 0.66 \\
\hline
\end{tabular}

erature review, our results may suggest that optimal timing for surgery might be after the 1st day of life. In practice, this may allow time for manifestation and workup of other congenital defects and perinatal issues, as well as medical optimization of the neonate. However, this data set does not allow for case-by-case examination of individual patient-level details, and care of the neonate encompasses many factors. Larger clinical-oriented series are warranted to examine the details of this question further.

The rates of concurrent and delayed shunt placement were low in this series. Shunts were recorded as being placed concurrently in $8 \%$ of cases and in delayed fashion within 30 days in $21 \%$ of cases. An additional 2 patients underwent delayed ventriculocisternostomy (with or without choroid plexus cauterization). In total, $31 \%$ of patients in this myelomeningocele closure cohort had CSF diversion surgery by 30-day follow-up. This is similar to a study using hospital discharge data from 2000 by Sin et al., ${ }^{17}$ which reported $35 \%$ of patients having shunt placement during the same hospitalization as their myelomeningocele repair. In a single-institution study of 54 cases of myelomeningocele from 1997 to 2006, Chakraborty et al. ${ }^{3}$ reported a shunt rate of $51.9 \%$ at 12 -month follow-up, with an average interval between myelomeningocele closure and shunt placement of 8 days. However, traditionally reported rates of shunting in this population have been around $70 \%$ to $90 \%, 9,10$ The relatively low CSF diversion rates seen in this study might be due to the fact that CSF diversion procedures beyond the 30-day time frame are not captured here; thus, the eventual total rate 
TABLE 4. Multivariate logistic regression for each 30-day outcome

\begin{tabular}{ccc}
\hline Variable & OR $(95 \% \mathrm{Cl})$ & p Value \\
\hline Complications & & \\
\hline Age at repair & & \\
\hline 0 days & $3.74(1.45-9.63)^{*}$ & $0.01^{*}$ \\
\hline$\geq 1$ day & 0.70 \\
\hline Return to op room events & \\
\hline Age at repair & & \\
\hline 0 days & $3.09(1.22-7.86)^{*}$ & $0.02^{*}$ \\
\hline$\geq 1$ day & Reference & \\
\hline Unplanned readmissions & & \\
\hline Weight category & & \\
\hline$<2500 \mathrm{~g}$ & $4.14(1.07-16.01)^{*}$ & \\
\hline$\geq 2500 \mathrm{~g}$ & Reference & \\
\hline
\end{tabular}

* $95 \% \mathrm{Cl}$ of odds ratio not inclusive of 1 or $p$ value $<0.05$.

of CSF diversion may not be reflected. There may also be a component of the evolution in surgical practice toward permissive ventriculomegaly. In further comparison with reported literature, the MOMS (Management of Myelomeningocele Study) trial reported actual rates of CSF shunt placement to be $40 \%$ in the prenatal myelomeningocele closure group and $84 \%$ in the postnatal closure group based on 158 mothers whose children were evaluated at 12 months. ${ }^{1}$ A follow-up study reported 1-year outcomes for the complete trial of 183 pregnancies, ${ }^{18}$ where rates of actual CSF shunting were $44 \%$ and $84 \%$, respectively, at 1 year. A full discussion of clinical criteria for shunting is complex and is addressed in ongoing literature. ${ }^{18}$ It is difficult to frame the results of this NSQIP study in comparison with published trials, as NSQIP reports on 30-day follow-up. A $31 \%$ CSF diversion rate for this NSQIP myelomeningocele cohort in the first 30 days yields the potential for a much larger percentage of this cohort to have undergone CSF shunting by 12-month follow-up, although this information is unknown.

Complication rates are consistent with previously published data. The 2-week length of stay and death rate of $2 \%$ seen in this analysis compares similarly to work by Kshettry et al. ${ }^{7}$ In this study, indications for return to operating room within 30 days of myelomeningocele repair are represented largely by hydrocephalus. Two-thirds of return to operating room cases are for initial treatment of hydrocephalus, while an additional $12 \%$ are for shunt revision or removal. Another $10 \%$ each are recorded for wound revision or repair of CSF leak. These numbers are consistent with pediatric neurosurgery literature. It is important to note that the label of "reoperations" representing return to the operating room in NSQIP-P should be interpreted in specialty-specific fashion.

\section{Limitations}

While the prospective national surgery quality improvement database gives a multicenter, nationwide report of 30-day outcomes, the collection of NSQIP-P participants is not nationally representative. Limitations also include lack of detail on clinical features specific to myelomenin- gocele repair compared with prospective or retrospective series focused on spina bifida treatment. There is no information on anatomical or neurological level of the lesion, which is a major predictor of function and long-term outcomes. Specialty-specific complications would also include changes in neurological status following surgery; this information is not collected. Surgical complexity of cases is not reflected. Operative technique is not known. Many intraoperative factors of concern to pediatric neurosurgeons are not recorded. For instance, size of the myelomeningocele defect alone may not be assumed to be a proxy for difficulty of closure; the level of the defect and the amount of tissue available for closure are not recorded. Technique and quality of dural closure are not known; use of a dural patch or tissue glue is not recorded. Intraoperative management of the placode is not noted. Case selection is dependent on CPT codes. In the case of myelomeningocele repair, CPT coding had high fidelity at our institution. We conducted an internal quality check with medical chart validation of NSQIP-P selected cases, which showed high fidelity of medical records with the NSQIP-P report of our institution's patients. Patient variables and postoperative complications are subject to bias during medical record review, although NSQIP-P provides detailed guides and data dictionaries to surgical clinical reviewers, as well as mechanisms for clarification and agreement with surgeon champions and NSQIP-P supervisors. Interreviewer reliability across NSQIP audits is high, with disagreement rates quoted around $2 \%$. Outcomes beyond 30 days are not reported in this database. Functional status and quality of life are not known. Development of Chiari II malformation symptoms, urological sequelae, orthopedic sequelae, downstream risk of shunt infection, and secondary tethering of the spinal cord cannot be addressed in this database limited to the 30-day postoperative period.

NSQIP-P does capture a number of clinical factors relevant to perioperative management and surgical outcomes in the pediatric population. This information is typically lacking or incompletely captured in administrative databases. ${ }^{21}$ Although the intent of NSQIP-P is to track postoperative complication rates, determinants of unplanned readmission, and factors leading to returns to the operating room, these outcomes must be interpreted within the context of the disease of interest. For instance, in this study return to operating room within 30 days for shunt placement is not necessarily an unexpected event, nor is it indicative of quality per se. Potentially preventable events, such as readmissions, may benefit from further examination specific to each institution's processes to identify opportunities for targeted enhancement. Families may also have more counseling regarding postoperative expectations. ${ }^{4,5,12,16}$

In terms of future directions, the design of the NSQIP-P to capture only the perioperative 30 -day time period is a major limitation. In our assessment, these data must be interpreted critically. The use of NSQIP-P for pediatric neurosurgery specialty-specific and disease-specific inquiry is previously largely unexplored, and we present notable shortcomings in this study. As such, NSQIP-P does not replace other research efforts. Clearly, these data cannot even begin to capture the chronic complexity of myelomeningocele care. While the overall goal of the American 
College of Surgeons NSQIP is to use data for benchmarking and quality improvement, our study highlights shortcomings of collecting surgery variables for pediatric neurosurgery diseases. Individual institutions and surgeons can refer to the collective national experience and subsequently approach information on 30-day perioperative outcomes with their own critical judgment. As NSQIP-P is an ongoing resource-intensive initiative across multiple pediatric hospitals in North America, it is important for pediatric neurosurgery to help interpret existing data in a proper clinical context and to highlight the rationale for advocating for disease-specific and specialty-specific data collection.

\section{Conclusions}

The NSQIP-P allows examination of 30-day perioperative outcomes from a national prospectively collected database. In this cohort, more than $25 \%$ of patients undergoing postnatal myelomeningocele repair experienced a complication within 30 days. Patients who had surgical repair within the first 24 hours of birth had a significantly higher perioperative complication rate than those who had surgery after 24 hours. We highlight limitations of investigating myelomeningocele repair using NSQIP-P and advocate the importance of disease-specific data collection.

\section{Acknowledgments}

The American College of Surgeons National Surgical Quality Improvement Program and the hospitals participating in the ACS NSQIP are the source of the data used herein; they have not verified and are not responsible for the statistical validity of the data analysis or the conclusions derived by the authors.

\section{References}

1. Adzick NS, Thom EA, Spong CY, Brock JW III, Burrows PK, Johnson MP, et al: A randomized trial of prenatal versus postnatal repair of myelomeningocele. N Engl J Med 364:993-1004, 2011

2. Attenello F, Tuchman A, Wen T, Nallapa S, Christian E, Cen SY: Infection rates following prolonged time to open neural tube repair: a national study. Neurosurgery 62 (Suppl 1):229, 2015 (Abstract)

3. Chakraborty A, Crimmins D, Hayward R, Thompson D: Toward reducing shunt placement rates in patients with myelomeningocele. J Neurosurg Pediatr 1:361-365, 2008

4. Fuchshuber PR, Greif W, Tidwell CR, Klemm MS, Frydel C, Wali A, et al: The power of the National Surgical Quality Improvement Program-achieving a zero pneumonia rate in general surgery patients. Perm J 16:39-45, 2012

5. Hall BL, Hamilton BH, Richards K, Bilimoria KY, Cohen ME, Ko CY: Does surgical quality improve in the American College of Surgeons National Surgical Quality Improvement Program: an evaluation of all participating hospitals. Ann Surg 250:363-376, 2009

6. Haq IZ, Akmal S, Chandler CL, Bassi S: Review of practices in myelomeningocoele repair at King's College Hospital, London. Br J Neurosurg 26:851-855, 2012

7. Kshettry VR, Kelly ML, Rosenbaum BP, Seicean A, Hwang L, Weil RJ: Myelomeningocele: surgical trends and predictors of outcome in the United States, 1988-2010. J Neurosurg Pediatr 13:666-678, 2014

8. Langham MR Jr, Walter A, Boswell TC, Beck R, Jones TL: Identifying children at risk of death within 30 days of sur- gery at an NSQIP pediatric hospital. Surgery 158:1481-1491, 2015

9. Mayer S, Weisser M, Till H, Gräfe G, Geyer C: Congenital myelomeningocele-do we have to change our management? Cerebrospinal Fluid Res 7:17, 2010

10. McLone DG, Dias MS: Complications of myelomeningocele closure. Pediatr Neurosurg 17:267-273, 1991-1992

11. McNamara ER, Kurtz MP, Schaeffer AJ, Logvinenko T, Nelson CP: 30-Day morbidity after augmentation enterocystoplasty and appendicovesicostomy: A NSQIP pediatric analysis. J Pediatr Urol 11:209.e1-209.e6, 2015

12. Piatt JH Jr: Thirty-day outcomes of cerebrospinal fluid shunt surgery: data from the National Surgical Quality Improvement Program-Pediatrics. J Neurosurg Pediatr 14:179-183, 2014

13. Pollack IF, Kinnunen D, Albright AL: The effect of early craniocervical decompression on functional outcome in neonates and young infants with myelodysplasia and symptomatic Chiari II malformations: results from a prospective series. Neurosurgery 38:703-710, 1996

14. Pollack IF, Pang D, Albright AL, Krieger D: Outcome following hindbrain decompression of symptomatic Chiari malformations in children previously treated with myelomeningocele closure and shunts. J Neurosurg 77:881-888, 1992

15. Ramasastry SS, Cohen M: Soft tissue closure and plastic surgical aspects of large open myelomeningoceles. Neurosurg Clin N Am 6:279-291, 1995

16. Saito JM, Chen LE, Hall BL, Kraemer K, Barnhart DC, Byrd C, et al: Risk-adjusted hospital outcomes for children's surgery. Pediatrics 132:e677-e688, 2013

17. Sin AH, Rashidi M, Caldito G, Nanda A: Surgical treatment of myelomeningocele: year 2000 hospitalization, outcome, and cost analysis in the US. Childs Nerv Syst 23:1125-1127, 2007

18. Tulipan N, Wellons JC III, Thom EA, Gupta N, Sutton LN, Burrows PK, et al: Prenatal surgery for myelomeningocele and the need for cerebrospinal fluid shunt placement. J Neurosurg Pediatr 16:613-620, 2015

19. Vandertop WP, Asai A, Hoffman HJ, Drake JM, Humphreys RP, Rutka JT, et al: Surgical decompression for symptomatic Chiari II malformation in neonates with myelomeningocele. J Neurosurg 77:541-544, 1992

20. Watson JC, Tye G, Ward JD: Delayed repair of myelomeningoceles. World Neurosurg 81:428-430, 2014

21. Yen IH, Khoury MJ, Erickson JD, James LM, Waters GD, Berry RJ: The changing epidemiology of neural tube defects. United States, 1968-1989. Am J Dis Child 146:857-861, 1992

\section{Disclosures}

The authors report no conflict of interest concerning the materials or methods used in this study or the findings specified in this paper.

\section{Author Contributions}

Conception and design: Lam, Cherian. Analysis and interpretation of data: Lam, Cherian, Staggers, Pan. Drafting the article: Cherian. Critically revising the article: Lam, Staggers, Pan, Lopresti, Jea. Reviewed submitted version of manuscript: Cherian, Staggers, Lopresti, Jea. Approved the final version of the manuscript on behalf of all authors: Lam. Statistical analysis: Cherian, Staggers. Administrative/technical/material support: Lam. Study supervision: Lam.

\section{Correspondence}

Sandi Lam, Department of Neurosurgery, Texas Children's Hospital/Baylor College of Medicine, 6701 Fannin St., CCC Ste. 1230, Houston, TX 77030. email: sklam@ texaschildrens.org. 